\title{
Moisture Vapor Resistance of Coated and Laminated Breathable Fabrics Using Evaporative Wet Heat Transfer Method
}

\author{
Hyun-Ah Kim
}

Citation: Kim, H.-A. Moisture Vapor Resistance of Coated and Laminated Breathable Fabrics Using Evaporative Wet Heat Transfer Method. Coatings 2021, 11, 1157. https://doi.org/ 10.3390/coatings 11101157

Academic Editor: Fabien Salaün

Received: 5 September 2021

Accepted: 20 September 2021

Published: 26 September 2021

Publisher's Note: MDPI stays neutral with regard to jurisdictional claims in published maps and institutional affiliations.

Copyright: (C) 2021 by the author. Licensee MDPI, Basel, Switzerland. This article is an open access article distributed under the terms and conditions of the Creative Commons Attribution (CC BY) license (https:/ / creativecommons.org/licenses/by/ $4.0 /)$.
Korea Research Institute for Fashion Industry, 45-26, Palgong-ro, Dong-gu, Deagu 41028, Korea; ktufl@krifi.re.kr

\begin{abstract}
This study examined the effects of the fiber materials, fabric structural parameters, and surface modification method on the moisture vapor resistance of coated and laminated fabrics according to the measuring method in comparison with evaporative wet heat transfer method. The moisture vapor resistance $\left(\mathrm{R}_{\mathrm{ef}}\right)$ of the coated and laminated fabrics measured using evaporative wet heat transfer method was much more precise than water vapor transmission rate (WVTR) and water vapor permeability (WVP) measured using American Society for Testing and Materials (ASTM) and Japanese Industrial Standard (JIS) methods. The correlation coefficient between $R_{e f}$ and WVTR in the laminated and coated polyethylene terephthalate (PET) fabric specimens was the highest, i.e., -0.833 , and -0.715 , in coated fabric specimens. Hence, selecting an appropriate measuring method according to the fabric materials and surface modification method is very critical. According to curvilinear regression analysis, the influential factor affecting breathability of the PET fabric specimens measured using evaporative wet heat transfer method was fabric weight $\left(\mathrm{R}^{2}=0.847\right)$ and fabric thickness $\left(R^{2}=0.872\right)$ in the laminated fabric specimens. Meanwhile, as per multiple linear regression, the most influential fabric structural parameters affecting the breathability of laminated fabric specimens measured using evaporative wet heat transfer method were the fabric density, weight/thickness, and weight followed by the fabric thickness $\left(R^{2}=0.943\right)$. These results would be valid for laminated breathable fabrics with characteristics within the range of this study and are of practical use for engineering laminated fabrics with high breathability.
\end{abstract}

Keywords: water vapor permeability; coated fabric; moisture vapor resistance; fabric structural parameter; surface modification method

\section{Introduction}

Clothing plays a very important role in maintaining the equilibrium of heat and moisture transfer for the wearer [1]. The water vapor permeability (WVP) while wearing clothing is a critical property for wear comfort. A high WVP allows the human body to cool down due to perspiration and evaporation. In addition, minimizing sweat build-up in clothing is important in cold environments [2]. On the other hand, many workers exposed to different atmospheric environments due to the nature of their work are critically influenced by the wear comfort of their work wear. Therefore, work wear with a satisfactory WVP level and appropriate protective characteristics is required. In particular, waterproof breathable fabrics need to maintain high breathability with stretch ability. In addition, perspiration absorption and fast-drying properties are needed in sportswear, such as climbing and jogging clothes. Therefore, early studies [1-11] examined the WVP of various fabrics focusing on the breathable characteristics according to the textile materials, fabric structural parameters, and surface modification, such as coating and laminating. Some studies [1-5] examined the moisture vapor resistance of knitted and woven fabrics using staple yarns made from cotton, polyester, wool, and their blended materials. Yoo et al. [6] examined the characteristics of simulated heat and moisture transport in fabrics and garments determined using a vertical plated sweating skin model. Yoo et al. [7,8] explored the effects of a layer array system and its wear trial assessment in a multilayer clothing system on the 
vapor permeability and condensation $n$ a cold-weather clothing ensemble. Lee et al. [9] examined the effects of the textile material and fabric structural factors on the WVP using statistical modeling. Kim et al. [10] reported the relationship between the specific clothing properties of fabrics made from artificial and natural fibers and their performance, such as dynamic moisture vapor transfer in a microclimate and its moisture and temperature measurements. Cubric et al. [11] explored the technical parameters affecting the moisture vapor resistance of knitted fabrics and clothing using a sweating guarded hot plate method and a thermal manikin. They reported an intermediate correlation $(R=0.7)$ between the moisture vapor resistance and moisture regain.

Moreover, the prominent fabric structural parameters affecting the moisture vapor resistance were the mass per unit area, fabric thickness, and tightness factor $(R=0.9)$. Most studies on the performance of waterproof breathable fabrics concentrated on the WVP characteristics. Many studies mentioned above on the WVP of waterproof breathable fabrics reported that the WVP of fabrics differs according to the fiber materials, and surface modification (finishing method), such as coating and laminating. Moreover, the method for measuring the WVP was a significant factor. In particular, many studies on the method for measuring the WVP have been performed [12-22]. Techniques to measure the WVP can be classified into two types. The first includes those that simulate sweating bodies or skin using the evaporative wet heat transfer method and are used mainly for research work. The second type is those used for routine quality control, development, and marketing purposes. Recently, Salz [12] suggested that the vapor transmission rates are often difficult to compare because of various test methods. He developed a laboratory measuring method for measuring the WVP using a heated cup method combined with an artificial rain condition. Lomax [13] reported a difference in the WVP according to the measuring methods, which was attributed to the difference in test conditions. Several studies [14-20] compared the performance characteristics of waterproof breathable fabrics using different measuring methods. Gibson et al. [14-16] examined the factors influencing the steady-state heat and water vapor transfer measurements for clothing materials using a hydrophobic and hydrophilic membrane laminated with two and three layers of fabrics. They measured the moisture vapor resistance using the most common techniques, such as guarded hot plate and cup-type water vapor transmission rate tests. Dolhan [17] compared the apparatus used to measure the water vapor resistance, where he reported a correlation between the upright cup method and the Canadian control dish method for measuring the moisture vapor resistance. Congalton [18] examined heat and moisture transport through textiles and clothing ensembles using the Hohenstein skin model. He reported a strong correlation between ISO 11092 [18], the Hohenstein measuring method, and the BS7209 [18] method. On the other hand, Lomax [13] reported an inverse correlation between the ISO 11092 [18] and BS 7209 [18] methods. Grettlon et al. [19] examined the correlation between the test methods used to measure water vapor transmission through fabrics. They reported a linear correlation between the moisture vapor resistance measured using the Gore-modified desiccant method and the BS 7209 [19], but this was limited to coated and laminated fabrics treated with the same polymer composition.

MaCullough et al. [20] studied the correlation among five measuring methods of WVP of 26 waterproof breathable fabrics. They reported a high correlation coefficient above 0.9 between the measuring methods of the WVP. Huang [21] examined influencing factors, such as air velocity and airflow direction affecting the moisture vapor resistance obtained in the ISO 11092 [18] method and compared them with the existing water vapor transmittance method. Huang [21] and his coworkers [22] reviewed and compared various test methods for measuring the water vapor transfer properties of fabrics. According to many studies explored previously, there was little study on the effects of the textile material, fabric structural parameters, and surface modification method affecting the moisture vapor resistance of the waterproof breathable fabrics and their difference according to the measuring methods. Therefore, this study examined the WVP and moisture vapor resistance of 73 waterproof breathable fabrics classified according to the fiber materials 
and surface modification methods. The WVPs by the upright cup and inverted cup methods and the moisture vapor resistance by the sweating guarded hot plate method using evaporative wet heat transfer were compared in terms of the fabric structural parameters and surface modification method. The experimental data were compared using correlation and regression analysis.

\section{Materials and Methods}

\subsection{Preparation of Specimens}

Seventy-three waterproof breathable woven fabrics were prepared and classified into fiber materials, such as nylon, polyester, and nylon/cotton or polyester/cotton, and surface modification method in terms of coated, laminated, dot laminated, and hot-melt laminated. The coated and laminated breathable fabric specimens according to fiber materials were mainly divided into two groups: nylon fabrics (38 items) and PET fabrics (35 items); nylon fabrics were composed of nylon $100 \%$ (24), nylon/cotton (6), and nylon dense (8), and PET fabrics were PET (13) and PET/cotton (22), which was nearly proportional to the amount sold in market. On the other hand, the numbers of the specimen according to surface modification method were divided in proportion to the production amount manufactured in finishing factories. Table 1 lists the classification of the breathable woven fabric specimens.

Table 1. Specimens according to materials and surface modification method.

\begin{tabular}{cccccc}
\hline $\begin{array}{c}\text { Specimen } \\
\text { Group }\end{array}$ & Materials & $\begin{array}{c}\text { No. of } \\
\text { Specimens }\end{array}$ & $\begin{array}{c}\text { Specimen } \\
\text { Group }\end{array}$ & $\begin{array}{c}\text { Surface } \\
\text { Modification } \\
\text { Method }\end{array}$ & $\begin{array}{c}\text { No. of } \\
\text { Specimens }\end{array}$ \\
\hline 1 & Nylon fabric & 24 & 1 & Laminated & 39 \\
2 & Nylon/cotton fabric & 6 & 2 & Coated & 14 \\
3 & PET fabric & 13 & 3 & Dotlaminated & 11 \\
4 & Nylon dense fabric & 8 & 5 & Hot-meltlaminated & 6 \\
5 & PET/cotton fabric & 22 & & Teflon finished & 73 \\
\hline Total & & 73 & & & \\
\hline
\end{tabular}

\subsection{Measurement of the Fabric Structural Parameters}

The fabric thickness was measured at a pressure of $2 \mathrm{gf} / \mathrm{cm}^{2}$ using a FAST-1 compression meter (CSIRO, Canberra, Australia). The weight was calculated using the mass of a $10 \mathrm{~cm} \times 10 \mathrm{~cm}$ fabric specimen. Twenty tests for the warp and weft densities were conducted for each fabric specimen. Table 2 lists the fabric structural parameters and surface modification method classified in terms of the laminated, coated, dot laminated, and hot-melt of each fabric specimen. As shown in Table 2, fabric density was widely distributed from loose to dense fabric, and fabric thickness was also distributed widely from thin to thick fabric. 
Table 2. Structural parameters and finishing method of the fabric specimens.

\begin{tabular}{|c|c|c|c|c|c|c|c|c|c|c|c|c|c|}
\hline \multirow[b]{2}{*}{$\begin{array}{l}\text { Specimen } \\
\text { No. }\end{array}$} & \multirow[b]{2}{*}{$\begin{array}{c}\text { Fiber } \\
\text { Material }\end{array}$} & \multirow[b]{2}{*}{$\begin{array}{c}\text { Surface } \\
\text { Modification } \\
\text { Method }\end{array}$} & \multicolumn{4}{|c|}{ Fabric Structural Parameters } & \multirow[b]{2}{*}{$\begin{array}{c}\text { Specimen } \\
\text { No. }\end{array}$} & \multirow[b]{2}{*}{$\begin{array}{c}\text { Fiber } \\
\text { Material }\end{array}$} & \multirow[b]{2}{*}{$\begin{array}{c}\text { Surface } \\
\text { Modification } \\
\text { Method }\end{array}$} & \multicolumn{4}{|c|}{ Fabric Structural Parameters } \\
\hline & & & $\begin{array}{c}\text { Thickness } \\
(\mathrm{mm})\end{array}$ & $\begin{array}{l}\text { Weight } \\
\left(\mathrm{g} / \mathrm{cm}^{2}\right)\end{array}$ & $\begin{array}{c}\text { Warp } \\
\text { Density } \\
\text { (ends/inch) }\end{array}$ & $\begin{array}{c}\text { Weft } \\
\text { Density } \\
\text { (picks/inch) }\end{array}$ & & & & $\begin{array}{c}\text { Thickness } \\
\text { (mm) }\end{array}$ & $\begin{array}{l}\text { Weight } \\
\left(\mathrm{g} / \mathrm{cm}^{2}\right)\end{array}$ & $\begin{array}{c}\text { Warp } \\
\text { Density } \\
\text { (ends/inch) }\end{array}$ & $\begin{array}{c}\text { Weft } \\
\text { Density } \\
\text { (picks/inch) }\end{array}$ \\
\hline 1 & $\mathrm{~N} / \mathrm{D}$ & \multirow{25}{*}{$\mathrm{L}$} & 0.125 & 35.52 & 290 & 150 & 38 & $\mathrm{~N} / \mathrm{C}$ & \multirow{14}{*}{$\mathrm{C}$} & 0.759 & 21.64 & 92 & 67 \\
\hline 2 & $\mathrm{~N}$ & & 0.439 & 24.82 & 88 & 130 & 39 & $\mathrm{P} / \mathrm{C}$ & & 0.427 & 22.94 & 128 & 84 \\
\hline 3 & $\mathrm{P}$ & & 0.276 & 11.75 & 125 & 80 & 40 & $\mathrm{~N}$ & & 0.391 & 15.67 & 160 & 56 \\
\hline 4 & $\mathrm{P}$ & & 0.317 & 14.93 & 120 & 80 & 41 & $\mathrm{~N}$ & & 0.276 & 14.18 & 125 & 80 \\
\hline 5 & $\mathrm{P}$ & & 0.305 & 16.52 & 120 & 80 & 42 & $\mathrm{P}$ & & 0.544 & 20.44 & 150 & 73 \\
\hline 7 & $\mathrm{P}$ & & 0.327 & 16.47 & 120 & 80 & 44 & $\mathrm{~N}$ & & 0.32 & 15.10 & 125 & 71 \\
\hline 8 & $\mathrm{P} / \mathrm{C}$ & & 0.344 & 16.10 & 165 & 65 & 45 & $\mathrm{~N}$ & & 0.349 & 20.68 & 120 & 79 \\
\hline 9 & $\mathrm{P}$ & & 0.305 & 15.02 & 100 & 75 & 46 & $\mathrm{~N}$ & & 0.398 & 19.76 & 110 & 85 \\
\hline 10 & $\mathrm{P}$ & & 0.19 & 9.70 & 220 & 120 & 47 & $\mathrm{P}$ & & 0.337 & 16.60 & 150 & 96 \\
\hline 11 & $\mathrm{P}$ & & 0.178 & 9.48 & 180 & 130 & 48 & $\mathrm{P}$ & & 0.212 & 10.94 & 135 & 97 \\
\hline 12 & $\mathrm{~N}$ & & 0.413 & 19.16 & 80 & 56 & 49 & $\mathrm{~N}$ & & 0.154 & 10.51 & 133 & 125 \\
\hline 13 & $\mathrm{~N}$ & & 0.305 & 14.18 & 130 & 80 & 50 & $\mathrm{P} / \mathrm{C}$ & & 0.251 & 13.38 & 140 & 85 \\
\hline 14 & $\mathrm{P} / \mathrm{C}$ & & 0.313 & 14.45 & 130 & 80 & 51 & $\mathrm{~N}$ & & 0.359 & 17.29 & 163 & 67 \\
\hline 16 & $\mathrm{~N}$ & & 0.298 & 13.24 & 155 & 75 & 53 & $\mathrm{~N}$ & & 0.359 & 19.45 & 156 & 90 \\
\hline 17 & $\mathrm{~N}$ & & 0.144 & 8.26 & 210 & 140 & 54 & $\mathrm{P} / \mathrm{C}$ & \multirow{11}{*}{$\mathrm{D}$} & 0.166 & 8.28 & 140 & 105 \\
\hline 18 & N/D & & 0.120 & 6.01 & 210 & 130 & 55 & $\mathrm{P} / \mathrm{C}$ & & 0.173 & 9.33 & 105 & 84 \\
\hline 19 & $\mathrm{P} / \mathrm{C}$ & & 0.137 & 6.46 & 136 & 144 & 56 & $\mathrm{~N}$ & & 0.178 & 9.38 & 103 & 76 \\
\hline 20 & N/D & & 0.125 & 5.99 & 205 & 136 & 57 & $\mathrm{~N}$ & & 0.193 & 9.34 & 105 & 82 \\
\hline 21 & $\mathrm{~N}$ & & 0.139 & 5.03 & 165 & 210 & 58 & $\mathrm{P} / \mathrm{C}$ & & 0.181 & 9.24 & 170 & 92 \\
\hline 22 & N/D & & 0.129 & 5.15 & 220 & 170 & 59 & $\mathrm{~N}$ & & 0.413 & 16.35 & 154 & 57 \\
\hline 23 & $\mathrm{~N}$ & & 0.120 & 5.92 & 320 & 200 & 60 & $\mathrm{P}$ & & 0.254 & 12.45 & 150 & 110 \\
\hline 24 & N/D & & 0.149 & 7.40 & 208 & 205 & 61 & $\mathrm{~N}$ & & 0.327 & 15.36 & 155 & 93 \\
\hline 25 & $\mathrm{P} / \mathrm{C}$ & & 0.251 & 8.79 & 88 & 88 & 62 & $\mathrm{~N}$ & & 0.410 & 14.85 & 150 & 95 \\
\hline 26 & N/D & & 0.122 & 5.34 & 240 & 175 & 63 & $\mathrm{P} / \mathrm{C}$ & & 0.376 & 15.34 & 130 & 93 \\
\hline 27 & N/D & & 0.137 & 5.67 & 225 & 190 & 64 & $\mathrm{~N}$ & & 0.405 & 16.57 & 100 & 60 \\
\hline
\end{tabular}


Table 2. Cont.

\begin{tabular}{|c|c|c|c|c|c|c|c|c|c|c|c|c|c|}
\hline \multirow[b]{2}{*}{$\begin{array}{l}\text { Specimen } \\
\text { No. }\end{array}$} & \multirow[b]{2}{*}{$\begin{array}{c}\text { Fiber } \\
\text { Material }\end{array}$} & \multirow[b]{2}{*}{$\begin{array}{c}\text { Surface } \\
\text { Modification } \\
\text { Method }\end{array}$} & \multicolumn{4}{|c|}{ Fabric Structural Parameters } & \multirow[b]{2}{*}{$\begin{array}{c}\text { Specimen } \\
\text { No. }\end{array}$} & \multirow[b]{2}{*}{$\begin{array}{c}\text { Fiber } \\
\text { Material }\end{array}$} & \multirow[b]{2}{*}{$\begin{array}{c}\text { Surface } \\
\text { Modification } \\
\text { Method }\end{array}$} & \multicolumn{4}{|c|}{ Fabric Structural Parameters } \\
\hline & & & $\underset{(\mathrm{mm})}{\text { Thickness }}$ & $\begin{array}{l}\text { Weight } \\
\left(\mathrm{g} / \mathrm{cm}^{2}\right)\end{array}$ & $\begin{array}{c}\text { Warp } \\
\text { Density } \\
\text { (ends/inch) }\end{array}$ & $\begin{array}{c}\text { Weft } \\
\text { Density } \\
\text { (picks/inch) }\end{array}$ & & & & $\underset{(\mathrm{mm})}{\text { Thickness }}$ & $\begin{array}{l}\text { Weight } \\
\left(\mathrm{g} / \mathrm{cm}^{2}\right)\end{array}$ & $\begin{array}{c}\text { Warp } \\
\text { Density } \\
\text { (ends/inch) }\end{array}$ & $\begin{array}{c}\text { Weft } \\
\text { Density } \\
\text { (picks/inch) }\end{array}$ \\
\hline 28 & $\mathrm{P} / \mathrm{C}$ & & 0.222 & 10.38 & 190 & 128 & 65 & $\mathrm{~N} / \mathrm{D}$ & \multirow{5}{*}{$\mathrm{H}$} & 0.349 & 13.43 & 210 & 72 \\
\hline 29 & $\mathrm{P}$ & & 0.198 & 11.51 & 165 & 120 & 66 & $\mathrm{P} / \mathrm{C}$ & & 0.381 & 16.35 & 122 & 57 \\
\hline 30 & $\mathrm{~N}$ & & 0.298 & 13.64 & 151 & 80 & 67 & $\mathrm{P} / \mathrm{C}$ & & 0.281 & 13.10 & 156 & 125 \\
\hline 31 & $\mathrm{P} / \mathrm{C}$ & & 0.378 & 16.87 & 112 & 88 & 68 & $\mathrm{P} / \mathrm{C}$ & & 0.291 & 14.77 & 87 & 72 \\
\hline 32 & $\mathrm{~N} / \mathrm{C}$ & & 0.552 & 17.56 & 152 & 88 & 69 & $\mathrm{P} / \mathrm{C}$ & & 0.386 & 14.49 & 120 & 76 \\
\hline 34 & $\mathrm{~N} / \mathrm{C}$ & & 0.461 & 18.44 & 155 & 112 & 71 & $\mathrm{~N}$ & \multirow{3}{*}{$\mathrm{T}$} & 0.186 & 8.88 & 108 & 78 \\
\hline 35 & $\mathrm{~N} / \mathrm{C}$ & & 0.305 & 10.46 & 285 & 220 & 72 & $\mathrm{P} / \mathrm{C}$ & & 0.176 & 8.04 & 127 & 96 \\
\hline 36 & $\mathrm{P} / \mathrm{C}$ & & 0.327 & 13.79 & 180 & 150 & 73 & $\mathrm{P} / \mathrm{C}$ & & 0.227 & 9.18 & 103 & 85 \\
\hline 37 & $\mathrm{~N} / \mathrm{C}$ & & 0.442 & 18.38 & 152 & 115 & & & & & & & \\
\hline
\end{tabular}

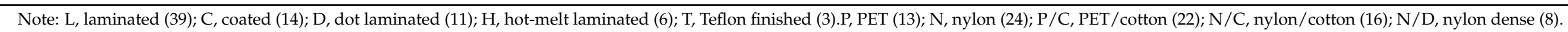




\subsection{Measurement of the Breathability of the Fabric Specimens}

The methods for measuring the WVP are divided into two types. The first is to simulate sweating bodies and skin using the evaporative wet heat transfer method, which is mainly used for research. The second is used for routine quality control, fabric development, and marketing purposes. In this study, three measuring methods were adopted to simulate the correlation between test methods according to fiber materials and various surface modification methods. These are the upright cup, inverted cup, and sweating guarded hot plate method, which were standardized in ASTM E96-80 [23], JIS L 1099 B-1 [24], and ISO 11092 [25] test methods, respectively.

\subsubsection{Measurement of the Water Vapor Transmission Rate}

The water vapor transmission rate (WVTR) was measured using the ASTM E96-80 [23], which was based on BS 7209 [26] and similar to the upright cup method, as shown in Figure 1a. Three fabric specimens, $7 \mathrm{~cm}$ in diameter, were prepared and conditioned at $20 \pm 2{ }^{\circ} \mathrm{C}$ and $\mathrm{RH}$ of $65 \% \pm 2 \%$ for $24 \mathrm{~h}$. The fabric specimen was placed $3 \mathrm{~mm}$ away from $\mathrm{CaCl}_{2}$ in an aluminum cup ( $6 \mathrm{~cm}$ in diameter and $2.5 \mathrm{~cm}$ in height); its surface faced the $\mathrm{CaCl}_{2}$ in the cup. Packing rubber with circular covering was clamped and sealed over the fabric specimen on the mouth of the aluminum cup to prevent water vapor from leaking between the fabric specimens and aluminum cup. Three aluminum cup assemblies with fabric specimens were placed in the conditioning room of $40 \pm 2{ }^{\circ} \mathrm{C}$ and $90 \% \pm 5 \% \mathrm{RH}$ for one hour. The water vapor transmission rate (WVTR, $\mathrm{g} / \mathrm{m}^{2} \cdot 24 \mathrm{~h}$ ) was calculated using Equation (1).

$$
\text { WVTR }=24 \mathrm{G} /(\mathrm{T} \cdot \mathrm{A})
$$

where WVTR is water vapor transmission rate $\left(\mathrm{g} / \mathrm{m}^{2} \cdot 24 \mathrm{~h}\right)$, and G/T is the slope of the straight line (weight loss per unit time, $\mathrm{g} / \mathrm{h}$ ). A is the test area $\left(\mathrm{m}^{2}\right)$.

\subsubsection{Measurement of the WVP}

The WVP $\left(\mathrm{g} / \mathrm{m}^{2} \cdot 24 \mathrm{~h}\right)$ was measured using the JIS L $1099 \mathrm{~B}-1$ [24] measuring method, which was similar to the inverted cup method, as shown in Figure 1b. Three specimens, $8 \mathrm{~cm}$ in diameter, were prepared and conditioned at $20 \pm 1{ }^{\circ} \mathrm{C}$ and $\mathrm{RH}$ of $65 \% \pm 5 \%$ for $24 \mathrm{~h}$. Three shallow impermeable and breathable cups were prepared and filled with a desiccant agent (potassium acetate). An assembly water bath was also prepared to contain distilled water. Distilled water was placed in the assembly bath on which a breathable cup was laid. The temperature was kept at $40 \pm 2{ }^{\circ} \mathrm{C}$ with an $\mathrm{RH}$ of $50 \% \pm 5 \%$. The fabric specimen was placed over a hydrophobic membrane, which was used to seal the mouth of the cup. The Polytetrafluoroethylene (PTFE) membrane was sealed below the desiccant to prevent moisture vapor from wetting the specimen placed below the desiccant. Therefore, the water vapor is transmitted through the fabric specimen from inside the assembly cup to the breathable cup surrounded by the desiccating agent (potassium acetate). The increase in mass of the breathable cup after a specific time has elapsed is equal to the mass of water vapor that passed through the fabric specimen. The WVP was calculated using Equation (2).

$$
\mathrm{P}=10 \times 24\left(\mathrm{~m}_{1}-\mathrm{m}_{2}\right) /(\mathrm{S} \times \mathrm{T})
$$

where $\mathrm{P}$ is WVP $\left(\mathrm{g} / \mathrm{m}^{2} /\right.$ day $) ; \mathrm{m}_{1}$ is the mass of the breathable cup after the test $(\mathrm{mg}) ; \mathrm{m}_{2}$, $\mathrm{S}$, and $\mathrm{T}$ are the mass of the breathable cup before the test $(\mathrm{mg})$, specimen area $\left(\mathrm{cm}^{2}\right)$, and testing time (h), respectively. 


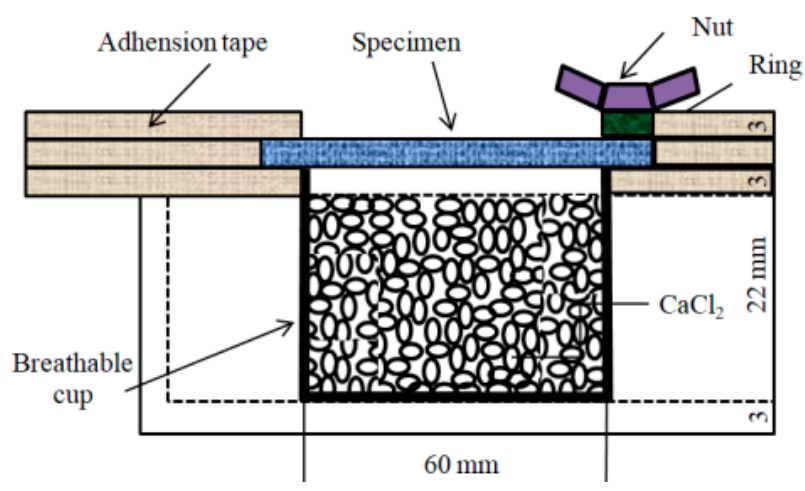

(a)

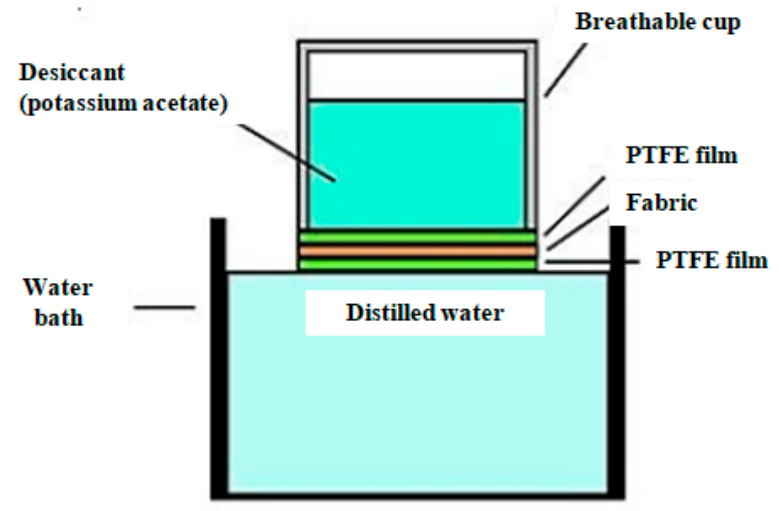

(b)

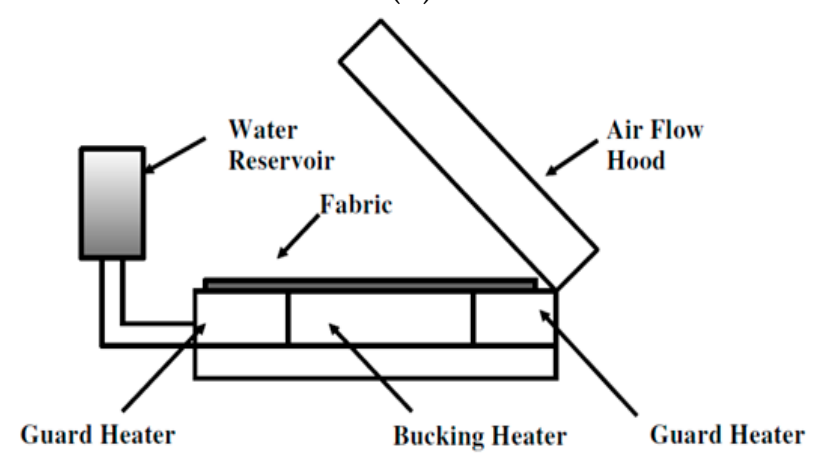

(c)

Figure 1. Measurement of the water vapor transmission rate. (a) Upright cup method, (b) inverted cup method, (c) sweating guarded hot plate method.

\subsubsection{Measurement of the Moisture Vapor Resistance}

The moisture vapor resistance $\left(\mathrm{R}_{\mathrm{ef}}, \mathrm{m}^{2} \cdot \mathrm{Pa} / \mathrm{W}\right)$ of the fabric was measured using a sweating guarded hot plate (Thermometer DAC, Cambridge, UK) according to the ISO 11092 [25] method, which uses an evaporative wet heat transfer method. Figure 1c presents a schematic diagram of this apparatus. A fabric specimen, $50.8 \mathrm{~cm} \times 50.8 \mathrm{~cm}$ in size, was prepared and conditioned in the standard atmosphere with an $\mathrm{RH}$ of $65 \%$ and a temperature of $20^{\circ} \mathrm{C}$. The specimen was placed over the PTFE membrane on a perforated metal surface on a hot plate, which was used to prevent the water on the perforated metal from wetting the fabric specimen. The temperature of the guarded hot plate and air in the chamber was kept at $35 \pm 0.5^{\circ} \mathrm{C}$ (i.e., human skin temperature) with an $\mathrm{RH}$ of $40 \%$ and an airspeed of $1 \mathrm{~m} / \mathrm{s}$. Moisture vapor resistance $\left(R_{\mathrm{ef}}\right)$ of the fabric was measured by measuring the evaporative heat loss $(H)$ in the steady-state condition, using Equations (3) and (4).

$$
\mathrm{R}_{\mathrm{e}, \mathrm{t}}=\frac{\left(p_{s}-p_{a}\right) A}{H}
$$


where, $R_{e, t}$ is the total resistance to evaporative heat transfer provided by the fabric system and air layer $\left(\mathrm{m}^{2} \cdot \mathrm{Pa} \cdot \mathrm{W}^{-1}\right) ; A$ is the area of the plate test section $\left(\mathrm{m}^{2}\right) ; p_{s}$ is the water vapor pressure at the plate surface $(\mathrm{Pa}) ; p_{a}$ is the water vapor pressure in air $(\mathrm{Pa})$; and $H$ is the power input $(W)$.

$$
\mathrm{R}_{\mathrm{e}, \mathrm{f}}=\mathrm{R}_{\mathrm{e}, \mathrm{t}}-\mathrm{R}_{\mathrm{e}}
$$

where, $R_{e, f}$ is the resistance to evaporative heat transfer provided by the fabric, and $R_{e, a}$ is the resistance measured for the air layer and liquid barrier. The arithmetic mean of five readings from each fabric specimen was calculated.

\section{Results and Discussion}

\subsection{WVTR Using the Upright Cup Method (ASTM E96-80)}

Figure 2 presents the WVTR using the upright cup method (ASTM E96-80) [23] of the fabric specimens according to the constituent fiber materials (Figure 2a) and surface modification method (Figure 2b) with the weight per thickness of the fabrics.

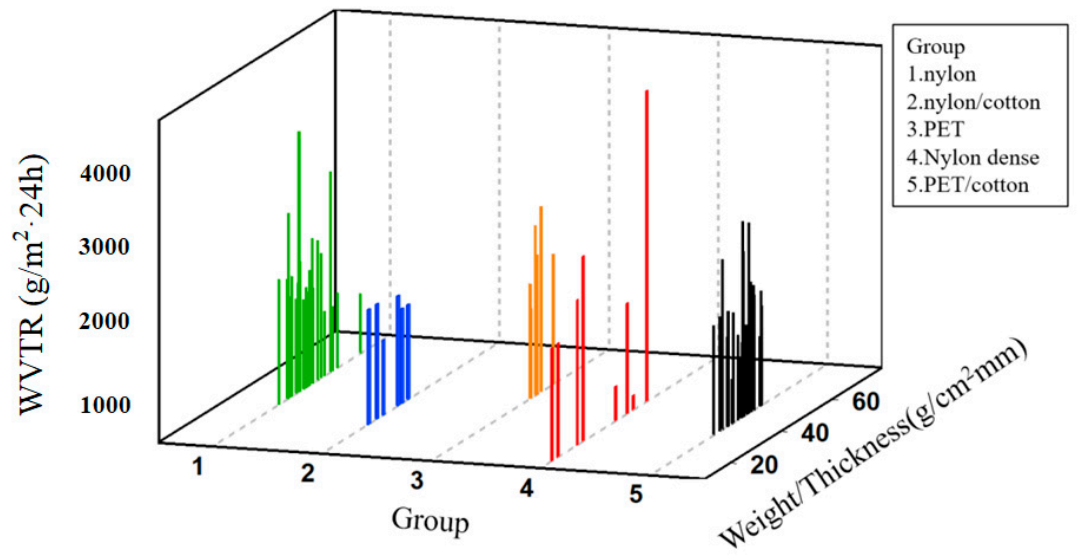

(a)

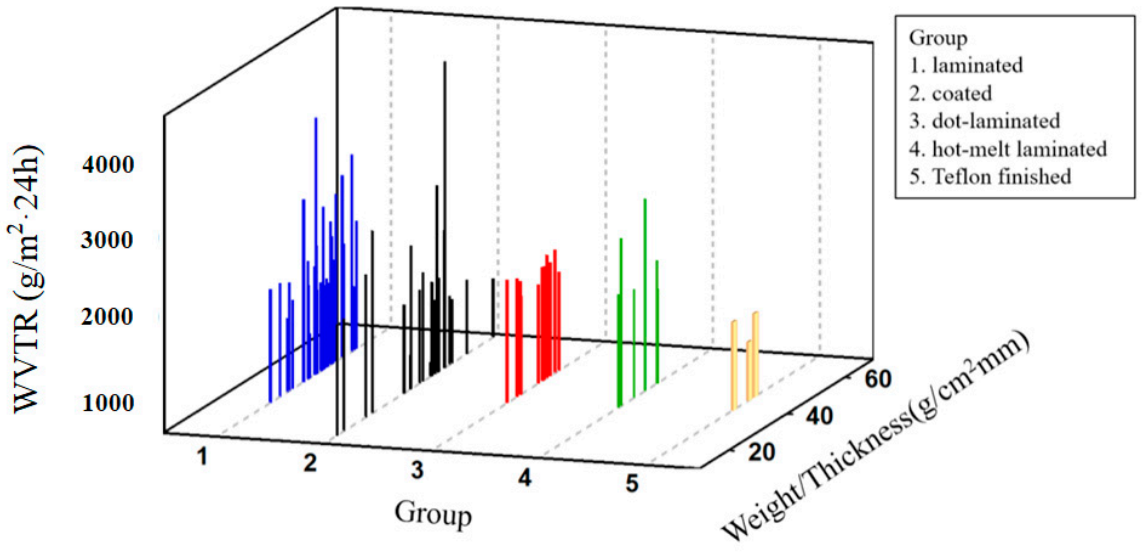

(b)

Figure 2. WVTR of the fabric specimens according to the constituent fiber materials and surface modification methods. (a) WVTR vs. fiber materials, (b) WVTR vs. surface modification method.

As shown in Figure 2a, the WVTR of the nylon (group 1), nylon dense (group 4), and PET (group 3) fabrics were widely distributed with the relevant weight per thickness of the fabric. In contrast, the blended woven fabrics with nylon and cotton (group 2) and blended woven fabrics with PET/cotton (group 5) exhibited a low WVTR and a similar WVTR according to weight per thickness of fabrics. In addition, as shown in Figure $2 b$, the WVTR of the fabrics treated with laminating (group 1) and coating (group 2) methods was much higher than that of the fabrics treated with dot laminating (group 3) and hot-melt 
laminating (group 4) methods. This suggests that the WVTR of the laminated and coated nylon and PET fabrics was superior to that of the cotton blended fabrics treated with dot and hot-melt laminated finishing. On the other hand, the WVTR of the fabrics according to fabric structural parameters was investigated by plotting the WVTR of the 73 fabric specimens as a function of the fabric thickness, weight, and density, as shown in Figure 3. Changes of the WVTR to the fabric density, thickness, and weight in Figure 3 were drawn to easily estimate their dependency on the fabric structural parameters using a red line, which will be compared with regression equation analyzed in Section 3.5.

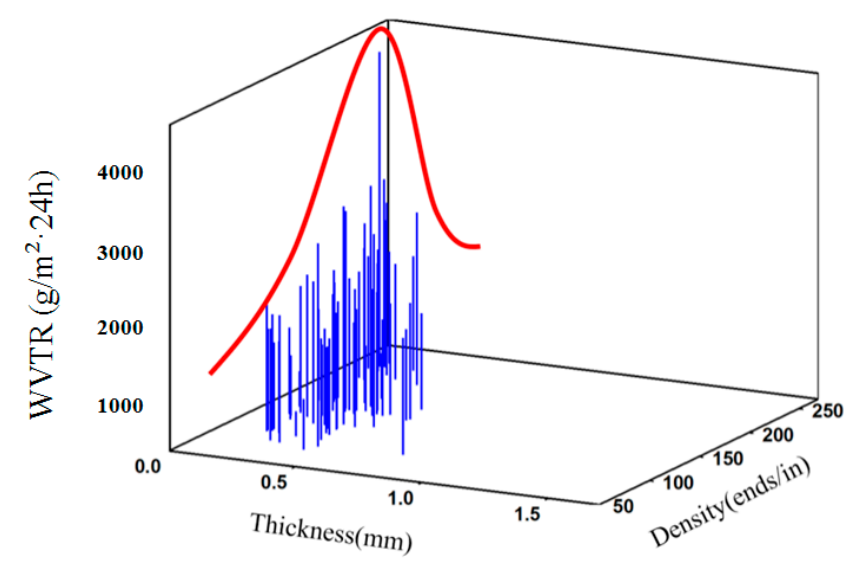

(a)

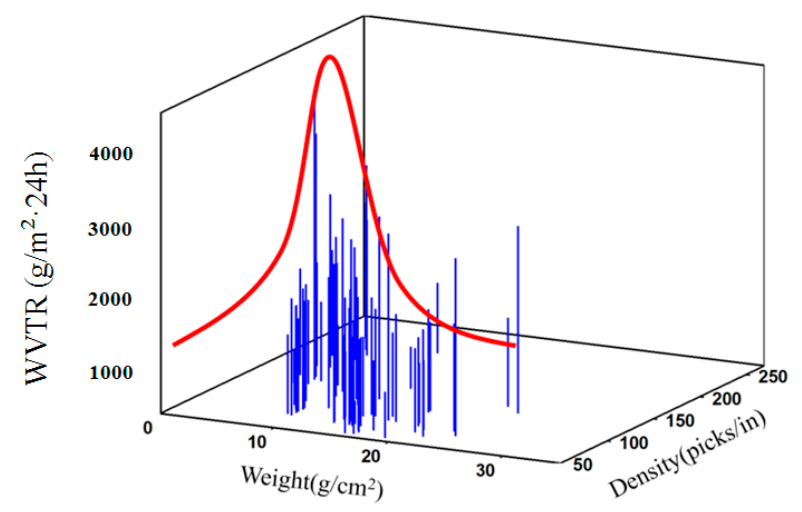

(b)

Figure 3. WVTR of the fabric specimens according to the fabric structural parameters. (a) WVTR vs. thickness and density, (b) WVTR vs. weight and density.

As shown in Figure 3, the WVTR of the 73 fabric specimens increased and then decreased with increasing fabric density (both warp and weft), fabric thickness, and weight. These results can be explained by the amount of air voids in the fabric, i.e., many air spaces in the fabrics under very low fabric density (high porosity) entrap the neighboring air and prevent moisture vapor flow from the inner layer to the outer one of the fabrics, which enables low WVTR. Successively, increasing fabric density decreases air spaces in the fabric, resulting in an increase of the WVTR up to the critical fabric density. However, the WVTR is decreased, as the fabric density is increased considerably and jammed, because highly jammed and dense fabrics have no voids in the fabric, which imparts a decrease of WVTR, which will be verified in the curvilinear regression analysis in the Section 3.5.

\subsection{Water Vapor Permeability Using the Inverted Cup Method (JIS L 1099B-1)}

Figure 4 shows the WVP of the 73 fabric specimens measured using the inverted cup method according to the fiber materials and surface modification method. 


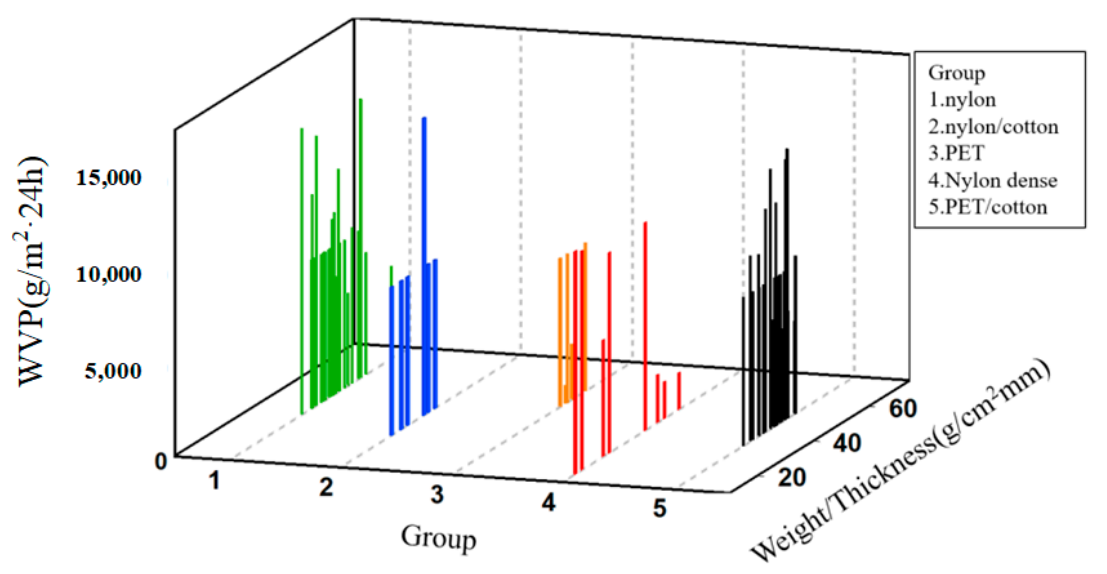

(a)

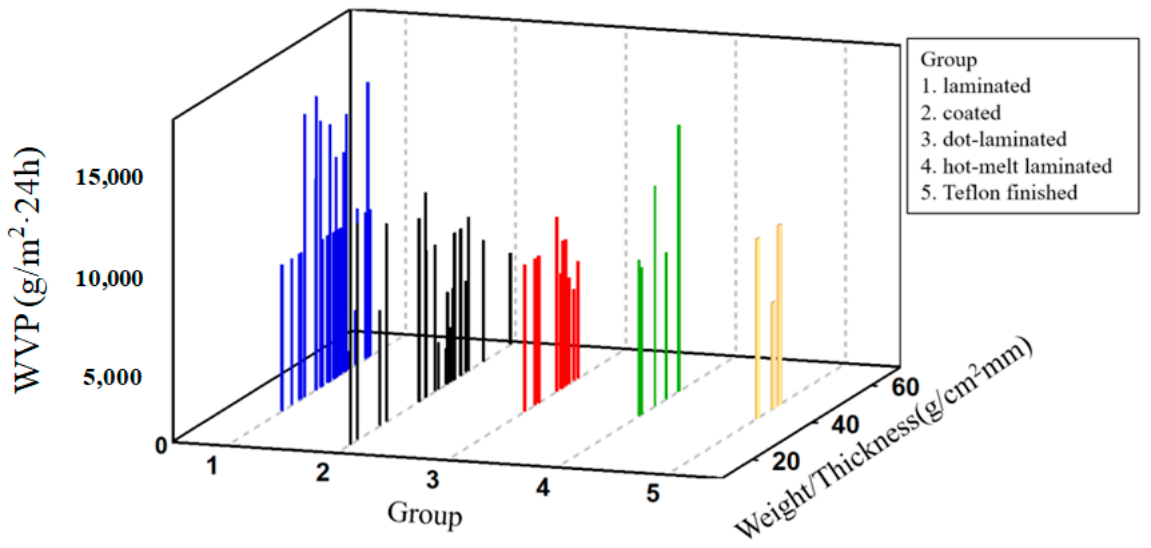

(b)

Figure 4. Water vapor permeability according to the materials and surface modification method. (a) WVP vs. materials, (b) WVP vs. surface modification method.

The distribution of water vapor permeability measured using the inverted cup method (Figure 4) according to the fiber materials and surface modification method differed slightly with that of the WVTR (Figure 2) measured using the upright cup method. As shown in Figure $4 \mathrm{a}$, the distribution of water vapor permeability of the nylon fabrics (groups 1 and 4) was much wider than that of the PET fabrics (group 3). In addition, the distribution of water vapor permeability (Figure 4a) of the blended fabrics with PET/cotton (group 5) was wider than that of the WVTR of groups 2 (nylon/cotton fabrics). These results were attributed to the difference of mechanism between two measuring methods, i.e., WVTR is assessed by transmission of water vapor by forced convection due to $\mathrm{CaCl}_{2}$ in upright cup, whereas in the inverted cup method, WVP is measured with hydrophobic PTFE film, which does not allow absorption of moisture in the fabric, giving WVP a much higher value than that of WVTR. Figure $4 \mathrm{~b}$ shows the water vapor permeability according to the surface medication method. The water vapor permeability of the laminated and coated fabric specimens (groups 1 and 2) was much higher than that of the dot laminated and hotmelt laminated fabric specimens (groups 3 and 4), which was similar to that of Figure $2 \mathrm{~b}$. Figure 5 presents a diagram of water vapor permeability of the 73 fabric specimens plotted as a function of the fabric thickness, weight, and fabric density. Curvilinear red lines in Figure $5 \mathrm{a}, \mathrm{b}$ were drawn to easily estimate the dependencies of WVP on the fabric structural parameter. 


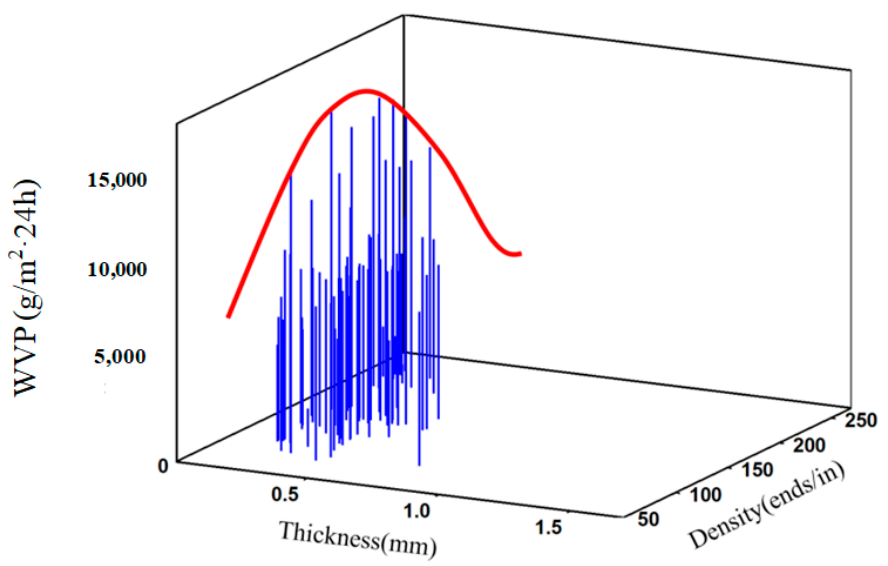

(a)

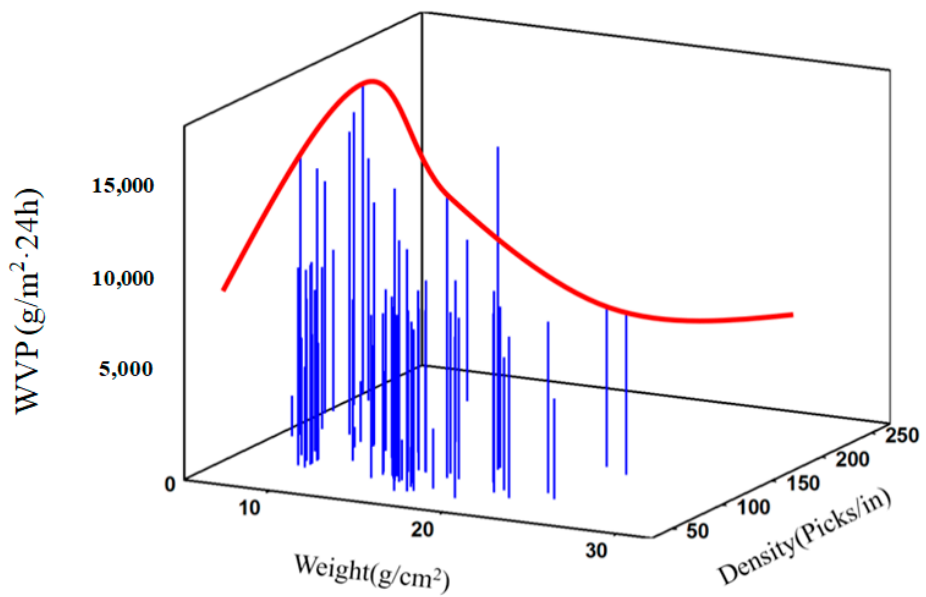

(b)

Figure 5. Water vapor permeability according to the fabric structural parameters. (a) WVP vs. fabric density and thickness, (b) WVP vs. fabric density and weight.

As shown in Figure 5a,b, the water vapor permeability of the 73 fabric specimens increased and then decreased with increasing fabric thickness, weight, and fabric density, which was similar to the case of WVTR measured using the upright cup method, as shown in Figure 3a,b. Comparing the WVTR measured using the upright cup method with the WVP measured using the inverted cup method, the WVTR of the 73 fabric specimens was distributed between 1000 and $4000\left(\mathrm{~g} / \mathrm{m}^{2} \cdot 24 \mathrm{~h}\right)$, and the WVP ranged between 5000 and $15,000\left(\mathrm{~g} / \mathrm{m}^{2} \cdot 24 \mathrm{~h}\right)$. The reason for higher WVP than WVTR is thought to be that the WVP method does not allow the passage of liquid water and leakage of water vapor absorbed during assessment because of the hydrophobic PTFE film placed on the fabric specimen. Superior WVTR and WVP were obtained in the nylon and PET laminated or coated fabrics with appropriate fabric density and thickness. However, to obtain the detailed relation between the two values and the influential factors affecting WVTR and WVP, statistical analysis between WVTR and WVP measured using two methods will be performed in next section.

\subsection{Moisture Vapor Resistance Using Evaporative Wet Heat Transfer Method}

Figure 6 presents the moisture vapor resistance $\left(R_{e f}\right)$ of the 73 fabric specimens measured using the evaporative wet heat transfer method. As shown in Figure 6a, the moisture vapor resistance of the nylon/cotton blended fabrics (group 2) and PET fabric (group 3) specimens was lower than that of the nylon fabrics (groups 1 and 4 ) and fabrics blended with PET/cotton (group 5), i.e., they exhibited a better WVP. These results are in contrast with those measured using the upright cup and inverted cup methods. Figure $6 \mathrm{~b}$ presents 
the moisture vapor resistance plotted as a function of the weight/thickness of the 73 fabric specimens according to the surface modification method. The moisture vapor resistance of the fabric specimens modified by the laminating (group 1) and coating (group 2) methods was higher than that of dot laminated (group 3) and hot-melt laminated fabric specimens (group 4). Hence, they exhibited poor breathability, which was also contrary to that measured using the upright cup and inverted cup methods. In addition, the change of $R_{e f}$ according to the weight/thickness was much greater than that of WVTR and WVP shown in Figures 2 and 4. This indicates that $R_{\mathrm{ef}}$ measured using the evaporative wet heat transfer method was much more precise than WVTR and WVP measured by the forced convection of $\mathrm{CaCl}_{2}$ and desiccating agent (potassium acetate). Figure 7 presents a diagram of the moisture vapor resistance according to the fabric structural parameters. Curvilinear red lines in Figure 7a,b were drawn to easily foresee the changes of WVP according to the fabric structural parameters. The graph shape of the moisture vapor resistance and fabric thickness and fabric density was concave (Figure 7a). In addition, the graph shape of the moisture vapor resistance against fabric weight and density was also concave (Figure $7 \mathrm{~b}$ ), which contrasted with the results in Figures 3 and 5, which showed convex shapes. This is because of the contrary definition between the moisture vapor resistance and WVTR and WVP. The correlation analysis between WVTR and moisture vapor resistance, and between WVP and moisture vapor resistance according to the fiber materials and surface modification method, is performed in the next section. Furthermore, contribution of fabric structural parameters affecting breathability according to surface modification method and materials is examined by regression analysis with a measuring method in the Section 3.5.

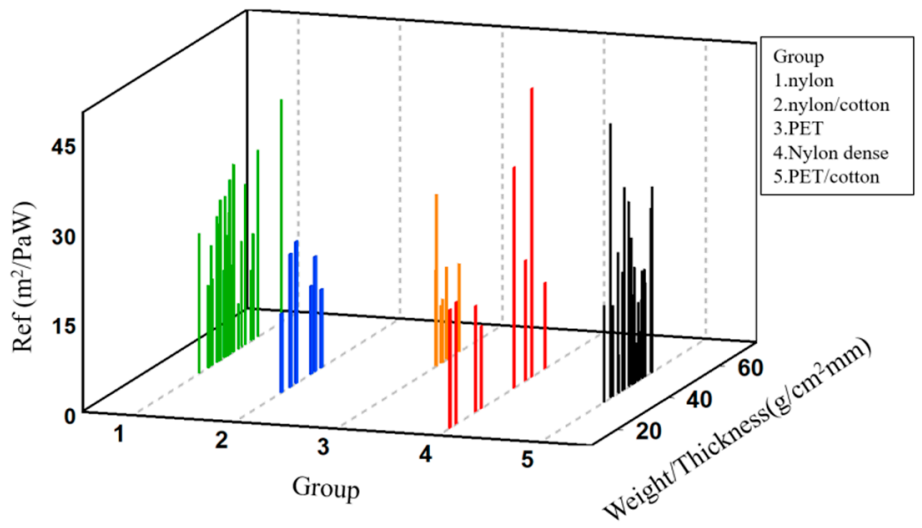

(a)

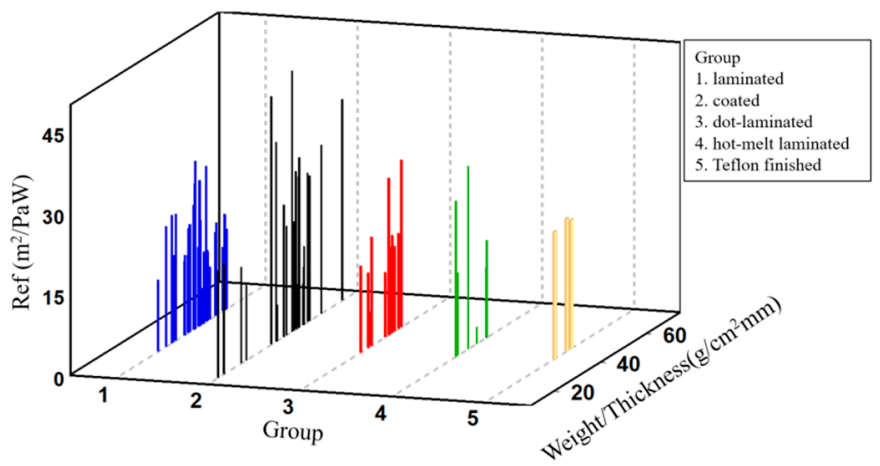

(b)

Figure 6. Moisture vapor resistance according to the materials and surface modification method. (a) $R_{\text {ef }}$ vs., materials and fabric structural parameters, (b) $R_{\text {ef }}$ vs. surface modification method and fabric structural parameters. 


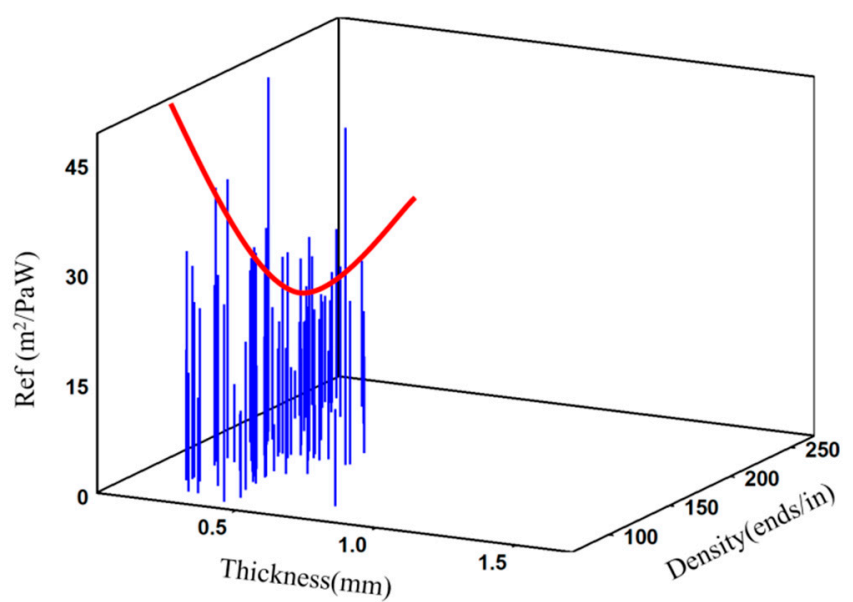

(a)

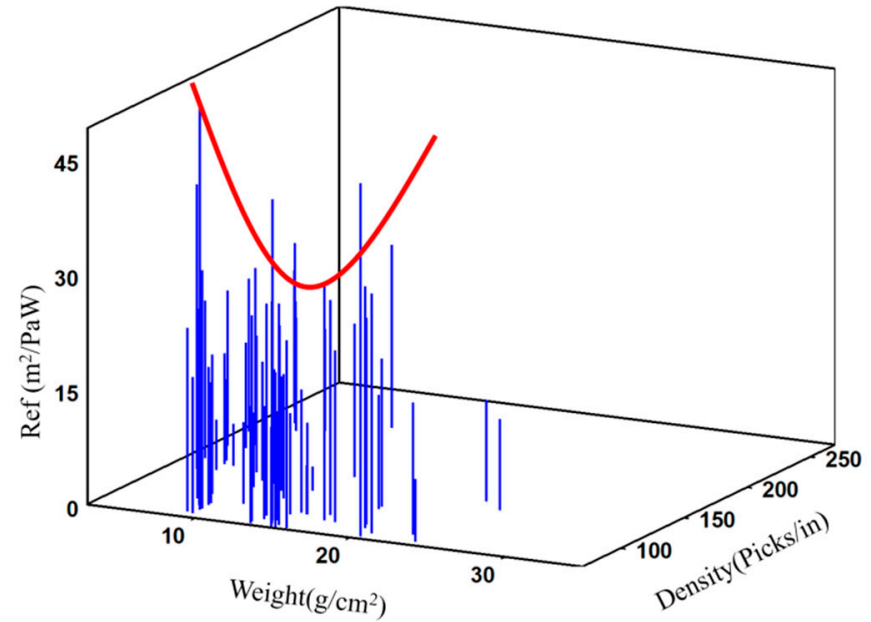

(b)

Figure 7. Moisture vapor resistance according to the fabric structural parameters. (a) $R_{\mathrm{ef}}$ vs. density and thickness, (b) $\mathrm{R}_{\mathrm{ef}} \mathrm{vs.}$ weight and density.

\subsection{Correlation Analysis between the Measuring Methods of Breathability}

In the previous section, the breathability of the 73 waterproof breathable fabric specimens made from the various fiber materials, surface modification methods, and fabric structural parameters was examined according to the three measuring methods. The effects of the fiber materials and surface modification methods on the measuring method of breathability are very important for understanding the difference between the methods for measuring breathability and the breathability characteristics. Therefore, correlation analysis between the measuring method of breathability was performed according to fiber materials and surface modification methods. Table 3 lists the correlation coefficients between measuring methods according to the fiber materials and surface modification methods. The correlation between ISO 11092 [25] and ASTM E96-80 [23] of the PET and coated fabrics was significant at the $99 \%$ confidence level, respectively. In addition, the correlation between ISO 11092 [25] and ASTM E96-80 [23] in 73 fabric specimens was significant at the $95 \%$ confidence level. 
Table 3. Correlation coefficient between measuring methods according to the fiber materials and surface modification methods.

\begin{tabular}{|c|c|c|c|c|c|c|c|}
\hline $\begin{array}{c}\text { Fiber } \\
\text { Materials }\end{array}$ & ISO/ASTM & $\begin{array}{l}\text { ASTM/ } \\
\text { JIS }\end{array}$ & ISO/JIS & $\begin{array}{c}\text { Surface Modification } \\
\text { Method }\end{array}$ & ISO/ASTM & $\begin{array}{l}\text { ASTM/ } \\
\text { JIS }\end{array}$ & ISO/JIS \\
\hline Total specimens & $-0.537^{b}$ & -0.104 & 0.021 & Total specimens & $-0.537^{b}$ & -0.104 & 0.021 \\
\hline PET & -0.833 & 0.064 & -0.002 & Laminated & -0.437 & 0.024 & 0.032 \\
\hline Nylon & $-0.616^{b}$ & 0.183 & -0.063 & Coated & $-0.715^{a}$ & -0.325 & 0.276 \\
\hline \multirow[t]{2}{*}{ Etc. } & -0.384 & 0.132 & 0.112 & Dot-laminated & -0.258 & -0.268 & -0.478 \\
\hline & & & & Hot melt laminated & $-0.710^{\mathrm{a}}$ & -0.710 & 0.138 \\
\hline
\end{tabular}

Note: ASTM, upright cup method; ISO, guarded hot plate method; JIS, inverted cup method. ${ }^{a}$ significant at 0.01 level, ${ }^{\mathrm{b}}$ significant at 0.05 level.

As shown in Table 3, the correlation coefficient of the 73 fabric specimens between the ISO $11092\left(R_{\mathrm{et}}\right.$ ) [25] and ASTM method (WVTR) was $-0.54,-0.10$ between the upright cup method (ASTM E96-80, WVTR) [23] and inverted cup method (JIS L 1099B-1, WVP) [24] and 0.02 between the ISO 11092 [25] and JIS L 1099B-1 [24]. These results were consistent with McCullough et al. [20] who reported-0.59 between ISO 11092 [25] and ASTM E96-80 [23] and 0.02 between the ISO 11092 [25] and JIS L 1099B-1 [24] methods using 26 waterproof breathable fabrics made from nylon and polyester. On the other hand, these results were in contrast to those obtained by Huang and Qian [22], who reported that the correlation coefficient between ISO 11092 [25] and JIS L 1099B-1 [24] for the regular fabric was -0.867 and -0.661 for laminated fabrics. Gorjanc et al. [5] reported that the correlation coefficient between the water cup method [27] and Permetest method [28] for eight types of cotton fabrics was $>0.9$, which was in contrast to the present findings and other studies. These results suggest that the measured breathability of the coated and laminated woven fabrics differs according to the measuring method, fabric materials, and surface modification method of fabrics, resulting in different correlation coefficients between the measuring methods according to the fabric materials and surface modification method. Hence, the correlation coefficient between the measuring methods was examined according to the fabric materials, such as polyester and nylon, and surface modification methods such as laminating and coating (Table 3). The correlation coefficient of the polyester fabrics between the ISO 11092 [25] and ASTM methods was -0.833 and -0.616 for nylon fabrics, which concurred with Huang and Qian [22] and McCullough et al. [20]. McCullough et al. [20] reported that the correlation coefficient between the two methods was -0.661 for laminated fabrics and -0.59 for WWB (waterproof, windproof, and breathable) shell fabrics. Regarding the correlation coefficient between the measuring method according to the surface modification method, the correlation coefficient between ISO 11092 [25] and ASTM E96-80 [23] methods was -0.715 for the coated fabrics and -0.710 for the hot-melt laminated fabrics. In contrast, the correlation coefficient between the ASTM E96-80 [23] and JIS L 1099B-1 [24] methods was -0.71 for the hot-melt laminated fabrics, showing a relatively higher correlation coefficient than the other surface modification methods. These results suggest that, when assessing the fabric breathability, the results measured by different measuring methods differ according to the fiber materials and surface modification method of the fabric. Therefore, selecting an appropriate measuring method according to the fabric materials and surface modification method is very important. Overall, of the measurement method of breathability and moisture vapor resistance $\left(R_{\mathrm{ef}}\right)$ measured using the evaporative wet heat transfer method was much more precise than WVTR and WVP, moreover, the $R_{\mathrm{ef}}$ of the PET coated fabrics measured using ISO 11092 [25] was highly correlated with WVTR measured using ASTM E96-80 [23] compared with other fabrics (nylon and laminated).

\subsection{Regression Analysis between the Breathability and Fabric Structural Parameters}

Lee and Obendorf [9] examined the WVTR of 15knitted and woven fabrics using the upright cup method (ASTM E-96-80) [23]. They reported that the main fabric structural parameters affecting the WVTR were the cover factor, fabric thickness, and void size of the fabrics, including the water absorption rate of the fibers and their characteristics. In addition, the determination coefficient $\left(R^{2}\right)$ between the WVTR and these parameters 
through regression analysis was 0.97 . However, this study had a limitation for using non-coated and non-laminated specimens, which is very important in breathability, and fewer specimens, which were insufficient for statistical analysis. In the present study, multiple regression analysis for the effect of fabric structural parameters on the breathability was performed with specimens divided according to the materials, surface modification method, and three types of measuring methods. Table 4 lists the curvilinear regression analysis of the breathability of PET and laminated fabric specimens in terms of the fabric structural parameters, which shows the results of PET and laminated fabrics above 0.6 for the determination coefficient $\left(R^{2}\right)$ with $5 \%$ significance level.

Table 4. Curvilinear regression analysis using the fabric structural parameters.

\begin{tabular}{|c|c|c|c|c|c|}
\hline $\begin{array}{l}\text { Material and } \\
\text { Surface } \\
\text { Modifacation } \\
\text { Method }\end{array}$ & $\begin{array}{c}\text { Measurement } \\
\text { Method }\end{array}$ & $\begin{array}{c}\text { Structural } \\
\text { Parameter }(x)\end{array}$ & Regression Equation & $\mathbf{R}^{2}$ & $p$-Value \\
\hline \multirow{4}{*}{ PET } & ASTM-96 & $\begin{array}{c}\mathrm{T} \\
\mathrm{W} \\
\mathrm{W} / \mathrm{T}\end{array}$ & $\begin{array}{c}y=-58,963.6 x^{2}-53,250.8 x+9562.7 \\
y=-42.6 x^{2}-1320.4 x+11,533.3 \\
y=-50.5 x^{2}+5486.7 x-146,199.9\end{array}$ & $\begin{array}{l}0.802 \\
0.844 \\
0.637\end{array}$ & $\begin{array}{l}<0.05 * \\
<0.05 * \\
<0.1\end{array}$ \\
\hline & \multirow[b]{2}{*}{ ISO 11092} & $\mathrm{~T}$ & $y=648.4 x^{2}-220.0 x+31.15$ & 0.839 & $<0.05^{*}$ \\
\hline & & $\mathrm{W}$ & $y=0.202 x^{2}-2.63 x+18.33$ & 0.847 & $<0.05^{*}$ \\
\hline & JIS L 1099B-1 & $\mathrm{D}$ & $y=-403 x^{2}+1015.8 x-55,872$ & 0.829 & $<0.05^{*}$ \\
\hline \multirow{4}{*}{ Laminated } & \multirow[b]{2}{*}{ ASTM-96 } & $\mathrm{W}$ & $y=-69.4 x^{2}+1769.5 x-8727.5$ & 0.640 & $<0.1$ \\
\hline & & $\mathrm{D}$ & $y=-0.83 x^{2}-175.8 x+10,927.1$ & 0.659 & $<0.1$ \\
\hline & ISO 11092 & $\begin{array}{l}\mathrm{T} \\
\mathrm{D} \\
\mathrm{W}\end{array}$ & $\begin{array}{c}y=1715.1 x^{2}-909.6 x+127.1 \\
y=0.002 x^{2}+4.74 x-220.4 \\
y=1.21 x^{2}-31.5 x+196.0\end{array}$ & $\begin{array}{l}0.872 \\
0.734 \\
0.611\end{array}$ & $\begin{array}{l}<0.05 * \\
<0.05 * \\
<0.1\end{array}$ \\
\hline & JIS L 1099B-1 & $\mathrm{W} / \mathrm{T}$ & $y=-37.5 x^{2}-2907.9 x+65,027.7$ & 0.663 & $<0.1$ \\
\hline
\end{tabular}

As shown in Table 4, in PET fabrics, the fabric thickness and weight were the influential factors affecting the breathability measured using the upright cup method (ASTM E9680) [23], with determination coefficients of 0.802 and 0.844 , respectively. The determination coefficients were 0.839 and 0.847 for the ISO 11092 [25] method using evaporative wet heat transfer method, which showed slightly higher $\mathrm{R}^{2}$ than ASTM method. The fabric density was the dominant factor with a determination coefficient of 0.829 in the inverted cup method (JIS L 1099B-1) [24]. It is very interesting that the influential factor affecting breathability differs according to the measuring method, i.e., thickness and weight in ASTM and ISO methods but density in JIS method, as shown in Table 4 . In addition, these results were in accordance with those of Figure 3, Figure 5, and Figure 7. Figures 3 and 5 indicate the results measured by ASTM and JIS methods, respectively, showing a convex shape (i.e., negative (-) in front of $x^{2}$ in curvilinear regression equations in ASTM and JIS methods of PET fabric, in Table 4), whereas, Figure 7 is for measurements using the ISO method, showing a concave shape (i.e., positive (+) in front of $x^{2}$ in equations in the ISO method in Table 4). On the other hand, the determination coefficient obtained by regression analysis according to the measuring method in the laminated fabrics was the highest $(0.872)$ in the ISO method using the evaporative wet heat transfer method, which indicates the exquisite measuring characteristics of this method compared to ASTM (WVTR) and JIS (WVP). In this curvilinear regression analysis, the breathability $(y)$ of fabrics was obtained by a quadratic term of predictor variables $(x)$ such as thickness, weight, and density of fabric. Meanwhile, multiple linear regression analysis was performed to obtain a polynomial model with linear term of fabric density, thickness, and weight. Table 5 lists the results of multiple linear regression analysis using backward regression method between the breathability and fabric 
structural parameters. As shown in Table 5, the determination coefficients $\left(R^{2}\right)$ of multiple regression analysis were much higher than those of the curvilinear regression analysis.

Table 5. Multiple linear regression analysis with the fabric structural parameters.

\begin{tabular}{ccccc}
\hline $\begin{array}{c}\text { Material and Surface } \\
\text { Modifacation } \\
\text { Method }\end{array}$ & $\begin{array}{c}\text { Measurement } \\
\text { Method }\end{array}$ & Regression Equation & $\mathbf{R}^{\mathbf{2}}$ & $\boldsymbol{p}$-Value \\
\hline PET & ASTM-96 & $y=1863.5-116.3 \mathrm{~W}-4.6 \mathrm{~W} / \mathrm{T}-13.8 \mathrm{D}$ & 0.887 & $<0.05^{*}$ \\
\cline { 2 - 6 } & ISO 11092 & $y=-13.4+2.5 \mathrm{~W}+0.05 \mathrm{~W} / \mathrm{T}+0.02 \mathrm{D}$ & 0.831 & $<0.05^{*}$ \\
\hline \multirow{2}{*}{ Laminated } & ASTM-96 & $y=60,386.4-147,757.2 \mathrm{~T}+2855.1 \mathrm{~W}-1116.4 \mathrm{~W} / \mathrm{T}-10.2 \mathrm{D}$ & 0.947 & $<0.01^{* *}$ \\
& ISO 11092 & $y=-2065.7+5016.8 \mathrm{~T}-91.6 \mathrm{~W}+37.6 \mathrm{~W} / \mathrm{T}+0.77 \mathrm{D}$ & 0.943 & $<0.01{ }^{* *}$ \\
& JIS L 1099B-1 & $y=118,939+307,656 \mathrm{~T}-6113 \mathrm{~W}+2665 \mathrm{~W} / \mathrm{T}-15.8 \mathrm{D}$ & 0.878 & $<0.05^{*}$ \\
\hline
\end{tabular}

* Significant at $95 \%$ level, ${ }^{* *}$ Significant at $99 \%$ level.

In PET fabric specimens, the breathability (WVTR) using the upright cup method (ASTM) was strongly dependent on the fabric weight, fabric weight per thickness, and fabric density, with a determination coefficient of 0.887 . Comparing these results with the previous result [9], the determination coefficient (0.887) of multiple linear regression analysis in this study was similar to that (0.87) of the adjusted $\mathrm{R}^{2}$ of model 1 of the previous findings [9]. In contrast, the determination coefficient was 0.831 for the ISO 11092 [25] method $\left(\mathrm{R}_{\mathrm{ef}}\right)$, which was similar to that of curvilinear regression analysis shown in Table 4. In particular, the determination coefficient between breathability (WVTR) measured using the upright cup method (ASTM E96-80) [23] and fabric structural parameters was 0.947, followed in order by 0.943 and 0.878 for the ISO $11092\left(R_{\mathrm{ef}}\right)$ [25] method and JIS L 1099B-1 method (WVP) [24], respectively. The most influential fabric structural factors affecting the breathability were the fabric density, weight per thickness, and weight followed by the fabric thickness. These results were slightly different from the previous findings [9], in which they revealed that fabric thickness was the first predictor of moisture vapor transmission through woven textiles, followed by cover factor and mean flow pore diameter. This may be due to the difference of textile materials, i.e., coated (laminated) PET (nylon) fabrics in this study and regular woven fabrics with staple yarns in the prior study [9].

\section{Conclusions}

The water vapor permeability of the coated and laminated breathable fabrics is governed by various factors in terms of fabric structural parameters and surface modification methods such as coating and laminating, furthermore it differs according to the measuring method. This study examined the breathability $\left(\mathrm{R}_{\mathrm{ef}}\right)$ of the coated and laminated breathable fabrics measured using the evaporative wet heat transfer method, which was compared with WVTR and WVP measured by ASTM and JIS methods through correlation and regression analysis. The changes of moisture vapor resistance $\left(R_{\mathrm{ef}}\right)$ according to the fabric weight/thickness was much greater than that of WVTR and WVP, which indicated that $R_{\text {ef }}$ measured using evaporative wet heat transfer method was much more precise than WVTR and WVP measured using conventional methods. The measured breathability of the coated and laminated woven fabrics differed according to the measuring method, resulting in different correlation coefficients between the measuring methods according to the fabric materials and surface modification method. The correlation coefficient between $\mathrm{R}_{\mathrm{ef}}$ (ISO) and WVTR (ASTM) in the laminated and coated PET fabric specimens was the highest, i.e., -0.833 and -0.715 in coated fabric specimens. Thus, selecting an appropriate measuring method according to the fabric materials and surface modification method is very important.

The influential fabric structural parameters affecting breathability of the coated and laminated PET fabrics measured using the evaporative wet heat transfer method were fabric weight $\left(R^{2}=0.847\right)$ and fabric thickness $\left(R^{2}=0.872\right)$ in the laminated fabrics by curvilinear regression analysis, which showed much higher $\mathrm{R}^{2}$ compared to other measuring method. This indicates that the ISO 11092 [25]. method $\left(R_{\mathrm{ef}}\right)$ measured using the evaporative wet 
heat transfer method was much more precise than WVTR and WVP measured using ASTM and JIS L 1099B-1 [24]. Furthermore, curvilinear regression equations obtained by a quadratic term of predictor variables were in accordance with the concave and convex graphs plotted with the breathability against fabric structural parameters of the 73 coated and laminated fabrics. Meanwhile, the most influential fabric structural parameters affecting the breathability of laminated fabrics measured using the evaporative wet heat transfer method were the fabric density, weight/thickness, and weight followed by the fabric thickness $\left(R^{2}=0.943\right)$ in multiple linear regression analysis, which was much higher $(0.943)$ than that $(0.872)$ of the curvilinear regression analysis.

This regression model would be valid for waterproof breathable fabrics with characteristics within the range of the fabrics in our specimens, i.e., for laminated fabrics woven of nylon and PET and cotton blended yarns. While based on the statistics of a specimen population, these findings are of practical use for engineering laminated fabrics with high breathability. For the prospective application of this study, it is proposed that, of the various method for measuring breathability, the moisture vapor resistance $\left(R_{\mathrm{ef}}\right)$ measured using the evaporative wet heat transfer technology is strongly recommended in the coated and laminated breathable fabrics, in research and development as well as in marketing. More detailed experiments in process with various materials and surface modification methods are needed for obtaining superior coated and laminated breathable fabrics for high-performance clothing.

Funding: This research is supported by Ministry of Culture, Sports and Tourism and Korea Creative Content Agency (Project Number: R 2019020030).

Institutional Review Board Statement: Not applicable.

Informed Consent Statement: Not applicable.

Data Availability Statement: The data presented in this study are available on request from the corresponding author.

Conflicts of Interest: The author declares no conflict of interest.

\section{References}

1. Zhou, L.; Feng, X.; Du, Y.; Li, Y. Characterization of liquid moisture transport performance of wool knitted fabrics. Text. Res. J. 2007, 77, 951-956. [CrossRef]

2. Das, B.; Das, A.; Kothari, V.K.; Fangueiro, R.; Araújo, M.D. Studies on moisture transmission properties of PV-blended fabrics. J. Text. Inst. 2009, 100, 588-597. [CrossRef]

3. Rego, J.M.; Verdu, P.; Nieto, J.; Blanes, M. Comfort analysis of woven cotton/polyester fabrics modified with a new elastic fiber, part 2: Detailed study of mechanical, thermo-physiological and skin sensorial properties. Text. Res. J. 2010, 80, 206-215. [CrossRef]

4. Du, Y.; Li, J. Dynamic moisture absorption behavior of polyester-cotton fabric and mathematical model. Text. Res. J. 2010, 80, 1793-1802. [CrossRef]

5. Gorjanc, D.Š.; Dimitrovski, K.; Bizjak, M. Thermal and water vapor resistance of the elastic and conventional cotton fabrics. Text. Res. J. 2012, 82, 1498-1506. [CrossRef]

6. Yoo, H.S.; Hu, Y.S.; Kim, E.A. Effects of heat and moisture transport in fabrics and garments determined with a vertical plate sweating skin model. Text. Res. J. 2000, 70, 542-549. [CrossRef]

7. Yoo, S.J.; Kim, E.A. Effects of multilayer clothing system array on water vapor transfer and condensation in cold weather clothing ensemble. Text. Res. J. 2008, 78, 189-197. [CrossRef]

8. Yoo, S.J.; Kim, E.A. Wear trial assessment of layer structure effects on vapor permeability and condensation in a cold weather clothing ensemble. Text. Res. J. 2012, 82, 1079-1091. [CrossRef]

9. Lee, S.S.; Obendorf, S.K. Statistical modeling of water vapor transport through woven fabrics. Text. Res. J. 2012, 82, 211-219. [CrossRef]

10. Kim, J.O.; Spivak, S.M. Dynamic moisture vapor transfer through textiles-Part II: Further techniques for microclimate moisture and temperature measurement. Text. Res. J. 1994, 64, 112-121. [CrossRef]

11. Cubric, I.S.; Skenderi, Z.; Havenith, G. Impact of raw material, yarn and fabric parameters, and finishing on water vapor resistance. Text. Res. J. 2013, 83, 1215-1228. [CrossRef]

12. Salz, P. Testing the Quality of Breathable Textiles, Performance of Protective Clothing: Second Symposium, ASTM Special Technical Publication 989; Mandorf, F.Z., Sagar, R., Bielson, A.P., Eds.; American Society for Testing and Materials: Philadelphia, PA, USA, 1988; p. 295. 
13. Lomax, G.R. Hydrophilic polyurethane coatings. J. Coat. Fabr. 1990, 20, 88-107. [CrossRef]

14. Gibson, P.W. Factors influencing steady-state heat and water vapor transfer measurement for clothing materials. Text. Res. J. 1993, 63, 749-764. [CrossRef]

15. Gibson, P.W.; Kendrick, C.E.; Rivin, D.; Charmchi, M.; Sicuranza, L. An automated water vapour diffusion test method for fabrics, laminates, and films. J. Coat. Fabr. 1995, 24, 322-345. [CrossRef]

16. Gibson, P.W.; Kendrick, C.E.; Rivin, D.; Charmchi, M. An automated dynamic water vapour permeation test method. Perform. Prot. Cloth. 1997, 6, 93-107. [CrossRef]

17. Dolhan, P.A. A comparison of apparatus used to measure water vapour resistance. J. Coat. Fabr. 1987, 17, 96-109. [CrossRef]

18. Congalton, D. Heat and moisture transport through textiles and clothing ensembles utilizing the Hohenstein skin model. J. Coat. Fabr. 1999, 28, 183-196.

19. Grettlon, J.C.; Brook, D.B.; Dyson, H.M.; Harlock, S.C. A correlation between test methods used to measure moisture vapor transmission through fabrics. J. Coat. Fabr. 1996, 25, 301-311. [CrossRef]

20. McCullough, E.A.; Kwon, M.; Shim, H. A comparison of standard methods for measuring water vapour permeability of fabrics. Meas. Sci. Technol. 2003, 14, 1402-1408. [CrossRef]

21. Huang, J. Review of test methods for measuring water vapor transfer properties of fabrics. Cell. Polym. 2007, 26, 167-191. [CrossRef]

22. Huang, J.; Qian, X. Comparison of test methods for measuring water vapor permeability of fabrics. Text. Res. J. 2008, 78, 342-352. [CrossRef]

23. ASTM E96-80. Standard Test Methods for Water Vapor Transmission of Materials; ASTM International: West Conshohocken, PA, USA, 2016. [CrossRef]

24. JIS L 1099; Testing Methods for Water Vapor Permeability of Textiles: JIS L 1099B-1; Upright Cup Method CH3COOH Test. 2012. Available online: http:/ / www,jisc.go.jp (accessed on 6 May 2021).

25. ISO 11092. Physiological Effects-Measurement of Thermal and Water-Vapour Resistance under Steady-State Conditions (Sweating Guarded-Hot Plate Test); International Organization for Standardization: Geneva, Switzerland, 2014.

26. BS 7209. Specification for Water Vapour Permeable Apparel Fabrics; British Standards Institution (BSI): London, UK, 2012.

27. Jakšič, D. Analytical method for determinating resistance to water vapor flow through flat fabrics. Tekstilec 1988, 31, 169-178.

28. Hes, L. Permetest Instrument; Sensora Instruments \& Consulting: Liberec, Czech Republic, 2005. 